\title{
Cucumber (Cucumis sativus) Breeding Line with Young Fruit Resistance to Infection by Phytophthora capsici
}

\author{
Rebecca Grumet ${ }^{1}$ and Marivi Colle \\ Department of Horticulture, Michigan State University, East Lansing, MI \\ 48824
}

Additional index words. phytophthora fruit rot, plant introduction

Cucumber (Cucumis sativus) production in the eastern and midwestern United States is subject to severe losses due to fruit rot caused by the soilborne oomycete pathogen, Phytophthora capsici (Granke et al., 2012; Sonogo and $\mathrm{Ji}, 2012$ ). P. capsici preferentially infects cucumber fruits, especially young fruit, while leaves and vines remain healthy (Ando et al., 2009, 2015; Gevens et al., 2006). Disease is manifested by extensive mycelial growth, sporulation, fruit rot, and tissue collapse. There are currently no commercial cucumber cultivars with resistance to this disease.

Our prior screening of young fruit from 1076 accessions from the U.S. cucumber PI collection identified three PIs with potential resistance: PI 109483 and PI 178884 from Turkey and PI 214049 from India (Colle et al., 2014). Although each accession had multiple plants with mean fruit scores in the resistant category, there were mixtures of resistant and susceptible individuals within the PI seed sample. Heterogeneity and heterozygosity among samples have been frequently observed for PI accessions, including for disease resistance in cucurbits (e.g., Davis et al., 2007; Donahoo et al., 2013; Wechter et al., 2011), making it necessary to stabilize resistance before further breeding efforts. PI 214049 from India was consistently very late or failed to produce female flowers and fruits in the field in Michigan conditions and so was not pursued further. Of the two PIs from Turkey, progeny of PI 109483 appeared to have stronger and more consistent resistance in subsequent generations as expressed by either no lesion development or lesions largely limited to the site of inoculation. Here we report the development of a PI 109483derived $\mathrm{S}_{6}$ progeny line with young fruit resistant to infection by $P$. capsici as

\footnotetext{
Received for publication 11 Oct. 2016. Accepted for publication 17 Nov. 2016.

This work was in part supported by MSU Project GREEEN, the Agriculture Research Fund of Pickle Packers International, and USDA-SCRI project 2011-51181-30661 and 2015-51181-24285. We thank Bill Chase and the MSU Horticulture Research, Teaching and Outreach Center for their assistance in the field. We thank Amy Iezzoni, Jim Kelly, and Chris Smart for their helpful reviews of the manuscript.
}

${ }^{1}$ Corresponding author. E-mail: grumet@msu.edu. a possible source of resistance for use in breeding programs.

\section{Origin}

PI 109483 is a landrace collected by H.L. Wesover and C.R. Enlow from the Konya bazaar in Turkey in 1935 (HTTPS:// NPGSWEB.ARS-GRIN.GOV/GRINGLOBAL/ ACCESSIONDETAIL.ASPX?ID=1129278). Seed was initially provided by the North Central Regional Plant Introduction Station, Ames, IA. In addition to variation for disease resistance, heterogeneity and heterozygosity were observed within the accession for morphological traits, as illustrated by differing fruit types within PI 109483 (Fig. 1). Fruit derived from different $S_{0}$ plants, PI 109483-2, and PI 109483-5 varied for the presence of prominent ribs, whereas progeny of selfpollinated PI 109483-5 segregated for wartiness and extent of bloom on the fruit surface. To develop true-breeding resistant lines, pure line selection was performed for five generations, resulting in the breeding line MSU109483-53.

\section{Disease Resistance}

Young fruit were harvested from individual plants and phenotyped for response to inoculation with $P$. capsici at each generation. Plants producing resistant fruit were selected for self-pollination. Plants were grown in the field for generations $\mathrm{S}_{0}, \mathrm{~S}_{1}, \mathrm{~S}_{2}$, and $\mathrm{S}_{4}$, and in the greenhouse for generation $\mathrm{S}_{3}$ and $\mathrm{S}_{5}$. Field plantings were performed at the Michigan State University Horticulture Teaching and Research Center, East Lansing, MI, in the summers of 2013-15. Plants within a family were treated as replicates and planted in a completely random design with 9-13 replicates per family. Plants were grown on $0.8 \mathrm{~m}$-wide plastic mulch with $3 \mathrm{~m}$ between rows and 2-m spacing within rows. Local standard commercial production guidelines were followed for fertilization and insect and weed control (Bird et al., 2005). Water was supplied by rain or trickle irrigation to provide $25 \mathrm{~mm}$ per week. Pollination was facilitated by bees. Once the period of fruit setting began, very young fruits, estimated to be $\approx 3-6 \mathrm{~d}$ postpollination ( $\mathrm{dpp}$ ) based on fruit size and blossom appearance, were harvested and brought to the laboratory for inoculation. Fruit were harvested as they became available from each plant two or three times a week during the period of early August to mid-September.

The harvested fruit were washed, surface sterilized by brief immersion in a $1 \%$ to $2 \%$ sodium hypochlorite solution, rinsed with water several times, and allowed to air-dry. Inoculations were performed with freshly prepared zoospore suspensions of $P$. capcisi isolate OP97 at $1 \times 10^{5}$ zoospores $/ \mathrm{mL}$ using the procedure of Colle et al. (2014). Two $30 \mu \mathrm{L}$ aliquots of the zoospore suspension were applied to each fruit. Incubation was performed under constant light at $23-25^{\circ} \mathrm{C}$ in covered trays lined with wet paper towels to maintain high humidity as described by Gevens et al. (2006). Fruit from the susceptible pickling type controls 'Vlaspik' (Seminis Vegetable Seed Inc., Oxnard, CA) and 'Gy14' (originally obtained from the University of Wisconsin and multiplied in the greenhouse) were included at each harvest to verify effectiveness of the inoculation procedure. The fruit were monitored daily for symptom development and obvious pathogen growth for a period of at least $5 \mathrm{~d}$. Disease ratings used for analysis were taken at $5 \mathrm{~d}$ post inoculation (dpi) using a 1-9 scale as described by Colle et al. (2014). Scores of 1-3 (i.e., no symptoms or minor symptoms limited to the point of inoculation) were considered resistant; 4-6 (i.e., moderate to extensive water soaking and/or limited necrosis, or mycelial growth), moderately susceptible; and 7-9 (i.e., moderate to extensive mycelium growth, sporulation, necrosis, and tissue collapse), highly susceptible.

Ten to twenty plants were tested for each family, and 10-60 young fruit were tested

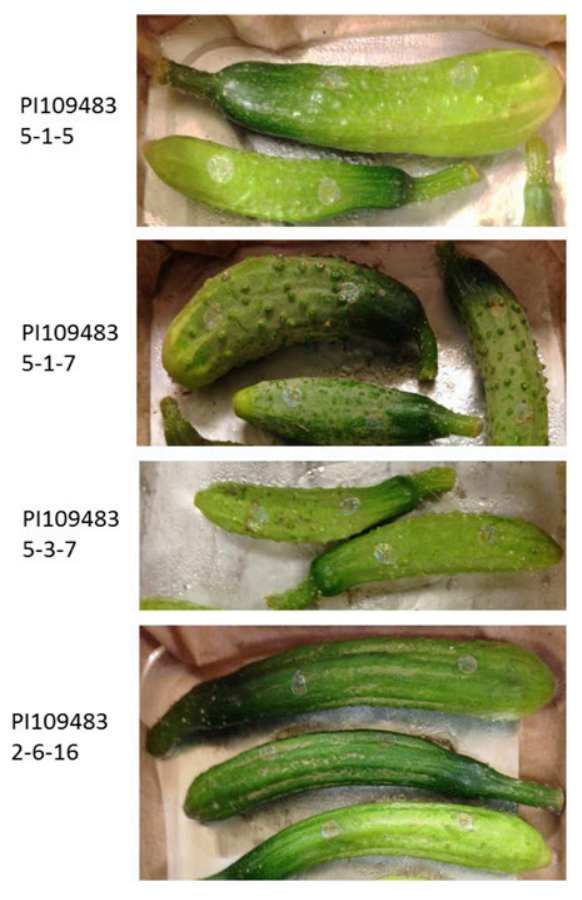

Fig. 1. Young fruit at $\approx 4 \mathrm{~d}$ postpollination from $\mathrm{S}_{2}$ families of PI 109483 showing variation for fruit traits such as shape, warts, spines, and ribs. 
for each plant, resulting in 200-400 fruits tested per family. The number of plants and fruits tested, range of mean values per plant, and mean values for each family are shown in Table 1. Data were analyzed using PROC
GLM in SAS (SAS Institute, Cary, NC) followed by multiple comparisons using Tukey's test, $P=0.05$ ). All of the PI 109483-5-3-derived S4 families and plants within those families showed resistance.
Table 1. Disease scores of young fruit of field-grown progeny of PI 109483 in response to inoculation with Phytophthora capsici ${ }^{\mathrm{z}}$, in 2015.

\begin{tabular}{lccccc}
\hline PI family & Generation & $\begin{array}{c}\text { No. of plants } \\
\text { tested }\end{array}$ & $\begin{array}{c}\text { No. of fruit } \\
\text { tested }\end{array}$ & $\begin{array}{c}\text { Range of plant mean } \\
\text { disease scores }\end{array}$ & $\begin{array}{c}\text { Family } \\
\text { mean } \pm \text { S.E. }\end{array}$ \\
\hline $109483-5-3$ & S2 & 12 & 286 & $2.85-6.01$ & $4.94 \pm 0.42 \mathrm{a}^{\mathrm{x}}$ \\
$109483-5-3-9-3$ & S4 & 9 & 247 & $2.58-4.90$ & $3.83 \pm 0.21 \mathrm{a}$ \\
$109483-5-3-18-8$ & S4 & 13 & 363 & $2.95-4.97$ & $3.71 \pm 0.20 \mathrm{a}$ \\
$109483-5-3-19-8$ & S4 & 9 & 227 & $2.80-4.89$ & $3.92 \pm 0.24 \mathrm{a}$ \\
$109483-5-3-24-10$ & S4 & 10 & 220 & $3.00-4.81$ & $4.03 \pm 0.20 \mathrm{a}$ \\
Vlaspik & & 3 & 177 & $6.30-8.77$ & $7.22 \pm 0.11 \mathrm{~b}$ \\
Gy14 & & 2 & 67 & $7.62-8.18$ & $7.90 \pm 0.28 \mathrm{~b}$ \\
\hline
\end{tabular}

${ }^{\mathrm{z}}$ Plants were grown in the field in 2015 . Young fruit $(\approx 4-6 \mathrm{dpp})$ were harvested and inoculated in the laboratory with $10^{5}$ zoospores $/ \mathrm{mL}$.

${ }^{\mathrm{y}}$ Disease rating at $5 \mathrm{~d}$ post inoculation on 1-9 scale. Ratings 1-3 indicate resistance, no symptoms or symptoms limited to the site of inoculation; 4-6 moderately resistant to moderate susceptible; and 7-9 highly susceptible, extensive mycelial growth, and fruit decay.

${ }^{x}$ Mean values followed by different letters are significantly different, Tukey's test, $P<0.05$.
Mean disease ratings at 5 dpi for fruits harvested from individual plants ranged from $<3$ (i.e., mild necrosis limited to the site of inoculation, indicating a resistance response by the fruit) to a maximum $<5$ (moderate water soaking without obvious mycelial growth). At 5 dpi, the control cultivars 'Vlaspik' and 'Gy14' had mean disease ratings of 7.2/9.0 and 7.9/9.0, respectively, with extensive pathogen growth, sporulation, and tissue collapse. Of the $>1000$ PI 109483-5-3 progeny fruit tested, sporulation occurred on less than $18 \%$ vs. $100 \%$ for 'Vlaspik' and 'Gy14' fruit. Examples of trays of young fruit from PI 109483-5-3 $S_{3}$ and $S_{4}$ plants and control 'Vlaspik' undergoing disease-resistance testing are shown in Fig. 2.

PI 109483 also has been previously identified as a potential source of resistance to belly rot (causal agent: Rhizoctonia solani) (Uchneat and Wehner, 1998) and to show low percent loss of fruit firmness in storage

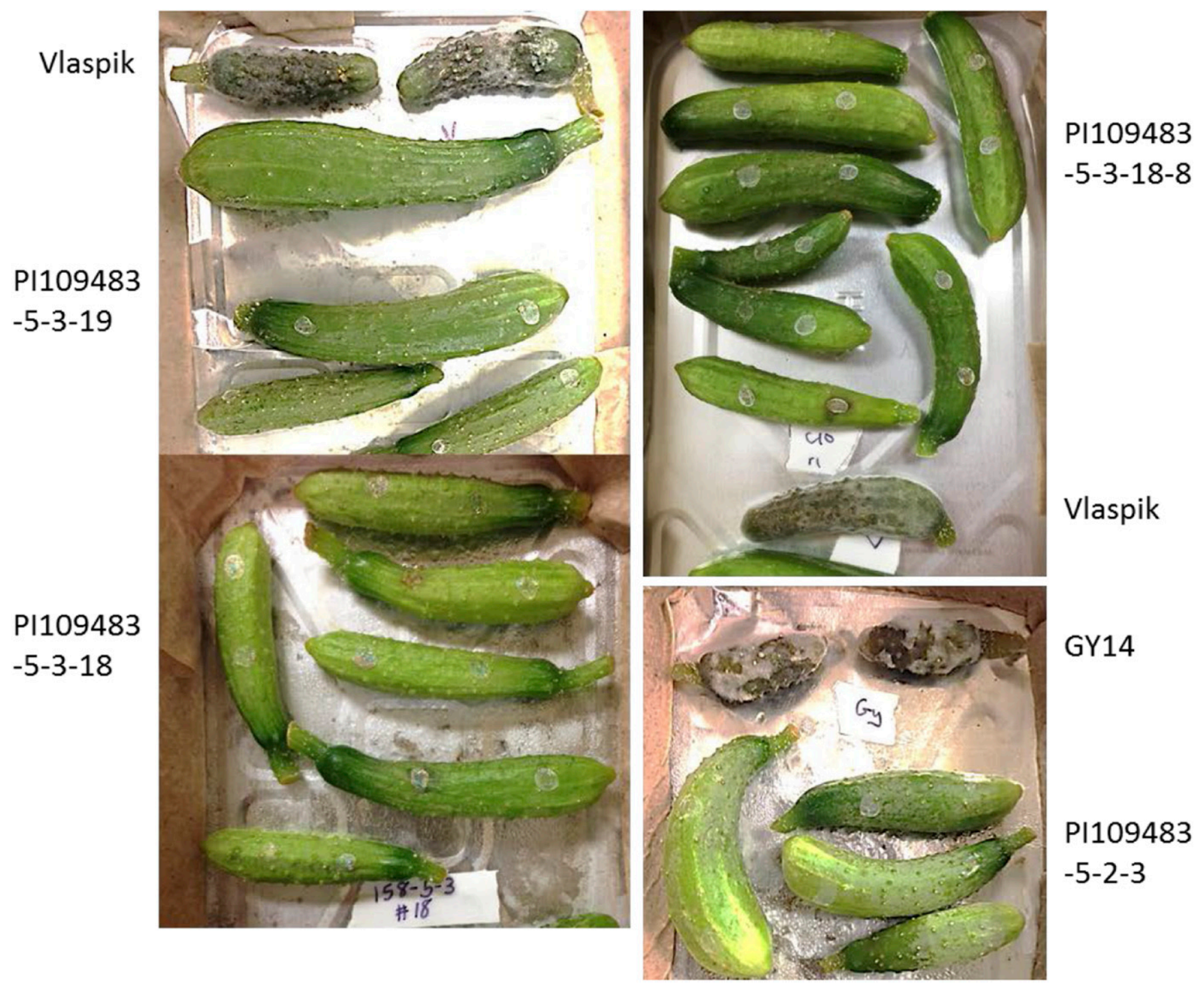

Fig. 2. Response of young fruits (3-6 d postpollination) from PI 109483 derived families to inoculation with $P$. capsici in comparison with susceptible control 'Vlaspik' and 'Gy14' fruit. The 'Vlaspik' and 'Gy14' fruit show extreme mycelial growth, sporulation, and tissue collapse. Most fruit from the selected PI 109483-derived families showed necrosis limited to the site of inoculation without further pathogen spread or fruit damage. Photos were taken $5 \mathrm{~d}$ post inoculation. 


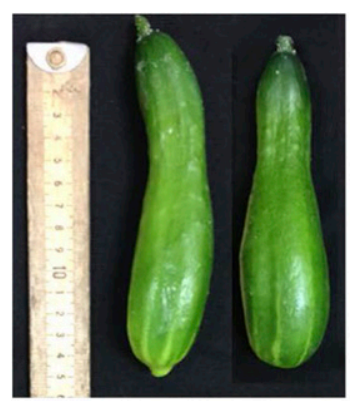

5-3-9-3

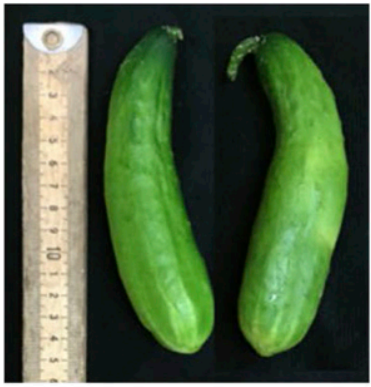

$5-3-18-8$

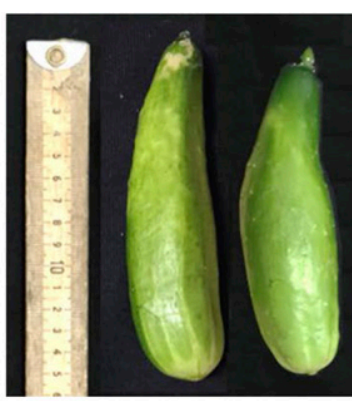

5-3-19-8

Fig. 3. Fruit type of the resistant PI 109483-53 S4 progeny families at 15-cm stage.

(Wehner et al., 2000). We have not tested whether the selected $\mathrm{S}_{5}$ families retained belly rot resistance.

\section{Fruit type}

Fruit type of the PI 109483-5-3-derived $\mathrm{S}_{4}$ families at 6-inch stage is shown in Fig. 3 . The fruit are comparatively deep green and smooth skinned with minor striping. Fruit shape is somewhat ovoid with a relatively long L/D ratio of 3.5-4.

\section{Availability}

Small samples of seed for research or trial may be requested from the corresponding author.

\section{Literature Cited}

Ando, K., K.M. Carr, M. Colle, B.N. Mansfeld, and R. Grumet. 2015. Exocarp properties and transcriptomic analsysis of cucumber (Cucumis sativus) fruit expressing resistance to Phytophthora capsici. PLoS One 10:e0142133, doi: 10.1371/journal.pone.0142133.

Ando, K., S.A. Hammar, and R. Grumet. 2009. Age-related resistance of diverse cucurbit fruit to infection by Phytophthora capsici. J. Amer. Soc. Hort. Sci. 134:176-182.

Bird, G., B. Bishop, E. Grafius, M. Hausbeck, L. Jess, W. Kirk, and W. Pett. 2005. Insect, Disease and Nematode Control for Commercial Vegetables. Michigan State University Ext. Bull. E-312, Cucumber section. p. 55-61.

Colle, M., E.N. Straley, S.B. Makela, S.A. Hammar, and R. Grumet. 2014. Screening the cucumber plant introduction collection for young fruit resistance to Phytophthora capsici. HortScience 49:244-249.

Davis, A.R., A. Levi, L. Tetteh, and T.C. Wehner. 2007. Evaluation of watermelon and related species for resistance to race $1 \mathrm{~W}$ powdery mildew. J. Amer. Soc. Hort. Sci. 132:790795.

Donahoo, R.S., W.W. Turechek, J.A. Thies, and C.S. Kousik. 2013. Potential sources of resistance in U.S. Cucumis melo PIs to crown rot caused by Phytophthora capsici. HortScience 48:164-170.

Gevens, A.J., K. Ando, K.H. Lamour, R. Grumet, and M.K. Hausbeck. 2006. A detached cucumber fruit method to screen for resistance to Phytophthora capsici and effect of fruit age on susceptibility to infection. Plant Dis. 90:1276-1282.

Granke, L.L., L. Quesada-Ocampo, K. Lamour, and M.K. Hausbeck. 2012. Advances in research on Phytophthora capsici on vegetable crops in the United States. Plant Dis. 95:1588-1600.

Sonogo, S. and P.S. Ji. 2012. Integrated management of Phytophthora capsici on solanaceous and cucurbitaceous crops: Current status, gaps in knowledge and research needs. Can. J. Plant Pathol. 34:479-492.

Uchneat, M.S. and T.C. Wehner. 1998. Resistance to belly rot in cucumber identified through field and detached-fruit evaluations. J. Amer. Soc. Hort. Sci. 123:78-84.

Wechter, W.P., A. Levi, K.S. Ling, C.S. Kousik, and C.C. Block. 2011. Identification of resistance to Acidovorax avenae subsp. citrulli among melon (Cucumis spp.) plant introductions. HortScience 46:207-212.

Wehner, T.C., N.V. Shetty, and L.G. Wilson. 2000. Screening the cucumber germplasm collection for fruit storage ability. HortScience 35:699-707. 